\title{
STUDENTSKA KONFERENCIJA U NOVOM SADU
}

(SUMMA STUDIORUM PHILOSOPHIAE, Treća studentska filozofska konferencija, Filozofski fakultet u Novom Sadu, 2930.6.2019)

DOI: https://doi.org/10.19090/arhe.2019.32.373-383

Odsek za filozofiju Filozofskog fakulteta u Novom Sadu, treću godinu zaredom bio je organizator međunarodne studentske konferencije SUMMA STUDIORUM PHILOSOPHIAE. Tema ovogodišnje konferencije bila je „Filozofija i emocije”, a datumi odvijanja konferencije bili su 29.6 i 30.6.2019. Kao i prethodnih godina studenti osnovnih i master studija su svoja izlaganja predstavljali $\mathrm{u}$ vremenskom roku od 15 minuta a nakon svake sesije jedan od tri zadužena moderatora (Lazar Atanasković, Miloš Miladinov i David Menčik) otvarali su diskusiju u trajanju od 30 minuta. Na konferenciji su takođe, učestvovala dva studenta doktorskih studija kao i jedan doktor filozofije koji su kao iskusniji ,ljubitelji mudrosti” imali čast da održe uvodna izlaganja u trajanju od 45 minuta. Konferencija je bila međunarodnog karaktera, budući da su pored učesnika iz Srbije učestvovali studenti sa univerziteta iz Hrvatske, Grčke i Slovenije. Posebno raduje

činjenica sve većeg odziva, budući da je treća po redu konferencija ujedno bila i najbrojnija kako po broju izlagača (26) tako i po broju gostujućih izlagača (13).

Skup su otvorile zamenik šefa Odseka za filozofiju doc. dr Una Popović i doc. dr Nevena Jevtić koje su naglasile da „Summa Studiorum Philosophiae“ postaje jedna od značajnijih i ozbiljnijih filozofskih konferencija u regionu. Popović je takođe naglasila da je za svaku pohvalu hrabrost mladih i perspektivnih studenata, ističući da je na prvoj konferenciji kao izlagač bio prisutan samo jedan student druge godine studija filozofije iz Novog Sada a da je ove godine ovom izazovu pristupilo čak šest studenata druge godine studija. Takođe je istaknuto da konferencija sve više poprima studentski karakter s obzirom da se u 
organizaciji ove godine kao moderator našao student četvrte godine studija filozofije David Menčik.

Konferenciju je otvorio dr Igor Cvejić, (Institut za filozofiju i društvenu teoriju; Beograd) sa temom „Afektivna intencionalnost ili kako integrisati objekat u emotivni događaj“. Cvejić izlaganje započinje prikazom različitih savremenih teorija emocija. Cvejić započinje suprotstavljajući teorije fizikalističkog karaktera koje prate Džejms-Langeov model i koje odriču emocijama intencionalnu usmerenost i kognitivističku teoriju emocija koja je emocije povezivala sa logičkim pojmovima verovanja i suđenja. Emotivna reakcija se, prema kognitivizmu, može prikazati preko zaključaka na osnovu pređašnjeg iskustva. Prikazano na primeru, ja kao pojedinac mogu imati sud o letenju avionom u kojem tvrdim da je letenje opasno, jer postoji mogućnost da se avion sruši i da moj život bude ugrožen. Takođe jednako bi bilo valjano suditi da letenje nije opasno, jer je statistički najsigurniji način saobraćanja od tačke a do tačke b. Ono što je nedostatak kognitivističke teorije emocija jeste nedostatak pridavanja značaja intencionalnosti iskustva emotivnog doživljaja. Da bi pronašao teoriju emocija koja više pažnje posvećuje intencionalnosti, Cvejić u daljem izlaganju ostavlja fizikalizam i kognitivizam ad acta fokusirajući se na nove fenomenološke pravce u filozofiji emocija. Kako autor tvrdi, fenomenološko razumevanje emocija, emotivni doživljaj shvata u njegovoj specifičnosti stavom da je nemoguće svesti na propozicionu logiku emocijama svojstven odnos sa svetom. Za fenomenološko shvatanje emocija važnim se pokazuju radovi Roberta C. Solomona, Pitera Goldija, Beneta Helma i Jana Slabija. Kod Solomona po prvi put zatičemo pojam afektivna intencionalnost. Prema Solomonu emocije više nisu samo usmerene ka svetskim događanjima, nego su i same upletene u svet. Cvejić izlaganje nastavlja prikazujući Goldijeve doprinose u filozofskom razumevanju emocija. Goldi, naime postavlja pitanje o važnosti svesnosti i refleksije emotivnog doživljaja. Preciznije označavanje karakteristika afektivne intencionalnosti zatičemo u filozofiji Helma i Slabija. Helm prikazuje važnost intencionalnog razumevanja u smislu odnosa subjekta 
prema događaju sa kojim se sastaje. Tokom „sastanka” subjekt procenjuje da li treba da se zalaže za objekat ili događaj ili da ga izbegava. Na primer, šahista tokom igranja partije svoje celokupno biće involvira zalažući se za pobedu nad protivnikom. S druge strane, računar koji igra šah takođe poseduje težnju da dođe do pobede. Ipak, kompjuter tu težnju ispoljava bez emotivne involviranosti, te nakon poraza neće žaliti, dok čoveku sigurno neće biti svejedno da li je pobedio ili ne. Cvejić završava stavom da u filozofiji Jana Slabija afektivnost emocija biva shvaćena po principu osećaja sposobnosti i nesposobnosti. Ovaj osećaj se pojavljuje kod „graničnog događaja". Na primer, kada se osoba uplaši za svoj život. U tom trenutku doživljava se nešto kao opasno, a u isto vreme oseća se i ranjivost u odnosu na objekat koji predstavlja opasnost.

Prvu sesiju, otvorila je Nesa Vrečer (Ljubljana) sa temom „Autobiographical Discourse: The Case of Jean-Jacques Rousseau“. Cilj izlaganja bio je prikaz Rusoovog diskursa o emocijama kroz analizu Rusoovih autobiografskih dela. Tokom izlaganja Vrečer je prikazala različitost emotivnih doživljaja u Rusoovoj filozofiji. U „Ispovestima” već na osnovu naslova dela možemo primetiti avgustinovski motiv razumevanja prošlosti iz perspektive sadašnjeg emotivnog stanja. $\mathrm{S}$ druge strane, u „Dijalozima”, Rusoovom hronološki poslednjem delu, imamo prikaz autorove apologije sopstvenih dela. Vrečer zaključuje da u oba autobiografska dela Ruso ostaje emotivno involviran, što je u redu, jer se ne-involviranost u delo pokazuje nemogućom u slučaju pisanja autobiografije.

Drugo po redu izlaganje održala je Mariam Ana Miku (Nacionalni i kapodistrijski univerzitet $\mathrm{u}$ Atini) naslovivši izlaganje „Love as dialectic way to Good, in Plato's Symposium”. Teza izlaganja bila je da je ljubav najvažnija emocija u Platonovoj filozofiji. Miku ljubav izjednačava sa težnjom uopšte i tvrdi da se reč težnja može prevoditi kao ljubav referišući na reč filozofija koja je, zapravo, težnja (ljubav) ka mudrosti. Prema autorkinom razumevanju „Gozbe”, ključnom se pokazuje činjenica da ljubav čini našu dušu boljom i da je ljubav oblik, ali i uslov obrazovanja in generis, 
kao što je ljubav prema mudrosti uslov za filozofiju.

Sledeće izlaganje održao je Vasilios Benteniotis (Nacionalni i kapodistrijski univerzitet u Atini) na temu „The human express of emotions and the collective emotions". Tokom izlaganja je dat prikaz razlike životinjskih i ljudskih emocija. Izlagač tvrdi da čovek, razumevajući sopstveni habitat, emocijama pripisuje pozitivnu karakteristiku koja mu omogućava život na način političkog bića. Upravo mogućnost čovekovog bivstvovanja na način zoon politikon-a predstavlja, prema Benteniotisu, ono što daje ljudima njihovu celovitost, koja se u ovom slučaju prikazuje u posedovanju kolektivnih emocija

Poslednje izlaganje u prvoj sesiji održali su Žika Petaković i Adriana Dondo (Novi Sad) na temu „Rusoovo razumevanje čoveka i emocija". Kao studenti filozofije, ali i komparativne književnosti, izlagači su prikazali Rusoovo stvaralaštvo iz vizure filozofije i teorije književnosti. Autori započinju prikazom primata emocija nad razumom u Rusoovom određenju čoveka iz dela „Ispovesti”. Autori naglašavaju da Ruso tvrdi da „,̌ovek prvo oseća pa tek onda misli”. Ovim stavom Ruso kontrira racionalističkom shvatanju primata razuma nad emocijama. Prema izlagačima, stav o primatu emocija ima važnost kako za potonju filozofiju, tako i za književnost. Ruso se zaista svrstava među začetnike sentimentalizma, književnog pravca poznatog i kao književnost osećajnosti, utičući svojom filozofijom na mnoga književna dela kao što je Geteovo rano delo ,Jadi mladog Vertera“, koje poseduje bogat prikaz emotivnih reakcija, od otuđenosti do tuge i samoubistva. Petaković i Dondo zaključuju svoje interdisciplinarno izlaganje prikazom važnosti koje je prikazivanje emocija dobilo $u$ opštoj populaciji u dobu neposredno pre Francuske revolucije.

Drugu sesiju otvorio je Bojan Grujić (Novi Sad) sa temom „Problem afektivnosti u Platonovoj teoriji pesništva". Grujićeva želja bila je prikazivanje različitog pogleda na Platonovu kritiku pesništva. Autor tvrdi da Platonova kritika ne poseduje isključivo negativne momente, nego i često previđane pozitivne momente. Referišući na dijaloge Država, Ijon $i$ Zakoni, Grujić tvrdi da pozitivno vrednovanje pesničke delatnosti 
dolazi iz činjenice da pesništvo kao medij obrazovanja može pozitivno uticati na paideia-u, pre svega ako se uzme u obzir da Platon paideia-u želi da organizuje stepenito. Autor zaključuje da opšti stav izbacivanja pesništva iz idealne države mora biti doveden $\mathrm{u}$ pitanje. Štaviše, pokazuje se da pesnička delatnost zaista ima svoje mesto i to kao neophodna za paideju valjano uređenog polisa.

Sledeće izlaganje održao je Nejc Kralj (Ljubljana) na temu „Kant and Moral Sensibility”. Kralj ističe da je odnos Kantove filozofije morala i Kantovog shvatanja čulnog prikaza osećanja putem emocija i želja u osnovi problema determinizma slobodne volje moralnog subjekta. Moralni subjekt je suštinski konačno racionalno biće, a u isto vreme $\mathrm{i}$ deo osećajnog sveta koji je regulisan od strane prirodnih zakona. Moralni zakon se postavlja kao onaj koji zahteva od nas potiskivanje želja zarad delanja prema zakonu. Kantov stav da „moralni praznici" nisu dozvoljeni bio je kritikovan od strane njegovih savremenika. Kralj za primer uzima Šilera koji u delu Über Anmut und Würde zamenjuje striktnu disciplinu razuma konceptom milosti, dostojanstva i lepe duše. Kralj zaključuje svoje izlaganje kritičkim osvrtom na prednosti Šilerove kritike Kantove filozofije, kao i mogućom Kantovom replikom Šileru koju Kant sam nije napisao.

Treće po redu izlaganje u drugoj sesiji održala je Sofia Fika (Nacionalni i kapodistrijski univerzitet $u$ Atini) na temu „Philosophy and Emotions in Renaissance Art”. Fika je težila da prikaže važnost odnosa filozofije i umetnosti u renesansi. Osnovni stav izlaganja je da su filozofske ideje u renesansi često bile praćene njihovim prikazom u materijalnoj formi. Autorka preko analize dela Ticijana, Veronezea i Botičelija tvrdi da je medij „koji govori 1000 reči“ pogodan kao pomoć filozofiji. U umetnosti se često ne može prikazati dubina ideje kao u filozofiji, ali umetničko delo lakše izaziva emotivne reakcije i zainteresovanost za prelazak ka filozofiji. Taj prelazak je moguć jer se u svakom od estetičkih elemenata prikazanim na materijalni način nalazi i njemu podležeći princip koji ide dublje od onoga slikovitog.

Drugu sesiju zatvorio je Goran Vujkov (Novi Sad) sa temom 
„Problem Platonove estetike i fenomenološkog prikazuje na lepog”. Vujkov je fokus izlaganja osećaju bola referišući na delo stavio na tri problema Platonove Nikole Graheka „Osećati bol i biti u estetike. Naime, na određenje bolu". Bol je izabran za primer lepote u Platonovoj filozofiji, zatim pitanje ontološke strukture lepote $\mathrm{i}$ pitanje mesta lepote u Platonovom filozofskom sistemu. Estetski doživljaj nužno sa sobom povlači emotivnost. Platonovo određenje lepote je igra jedinstva i mnoštva. Izvesno je iz različitih teza $u$ različitim dijalozima da Platonovo određenje lepog neupitno zavisi od glavne teme dijaloga u kojem se pitanje lepog pojavljuje. Vujkov zaključuje svoje izlaganje tvrdnjom da mnoštvenost govora o lepom ne negira jedinstveni karaktera određenja lepote u Platonovom opusu.

Andrija Jurić (student doktorskih studija filozofije u Novom Sadu) otvorio je popodnevni program plenarnim izlaganjem na temu „Neurofiziološka i fenomenološka osnova emocija". Jurić počinje izlaganje obrazlažući sam naslov. Neurofiziologija predsta-vlja moždane procese, stanja i regione procesuiranja informacija koji podležu mentalnim stanjima. $\mathrm{S}$ druge strane, pod fenome-nološkom osnovom emocija razu-me se subjektivna dimenzija mentalnih stanja. Jurić odnos neurofiziološkog upravo zbog svoje specifičnosti. Neka pitanja koja Jurić postavlja su: Da li je bol emocija? Zar nije bivstvovanje u bolu isto kao i osećanje boli? Izlagač tvrdi da je na prvo pitanje nemoguće dati siguran odgovor. Jurić se zato ograđuje od odgovora i kaže da je bol rudimentno emotivno stanje koje se može pojaviti samostalno ili inkorporirano u složene emocije. Odgovor na drugo pitanje deluje logično, naravno da je bivstvovanje u bolu jednako sa osećajem boli. Jurić se slaže da je to slučaj osim u slučajevima poremećaja kao što su kongenitalna analgezija, stanje u kojem je pacijent potpuno neosetljiv na bol i asimbolija bola, stanje u kojoj je osoba indiferentna prema osećaju bola. Jurića upravo zanimaju disocijativni sindromi bola u kojima se na odličan način vidi prevođenje onog neurofiziološkog mnoštva u fenomenološko jedinstvo.

Treću sesiju otvorio je Lazar Trifunović (Novi Sad) sa temom „Emocije kao pokretač ljudskog delovanja". Trifunović smatra da je većina filozofskih koncepcija 
počivala na bezgraničnoj veri $\mathrm{u}$ ljudski razum često zanemarujući ulogu emocija u ljudskom delanju. Autor tvrdi da su emocije inicijalni uzročnici bilo koje reakcije u praktičkoj sferi, dok je funkcija razuma refleksivno vrednovanje situacije koje nikad ne može da se pojavi pre uplitanja emocija. Bez osećaja radosti, nezadovoljstva, simpatije, antipatije i drugih sličnih osećanja, nema ni praktičkog života kakvog poznajemo i upravo je iz toga razloga ratio manje važan $\mathrm{u}$ pitanjima praktičkog života nego osećanja. Konačni sud je da bez emocija ne bi bilo delanja, jer razum sam po sebi ne može da bude okidač za delanje. Opravdavajući svoje stanovište, autor ističe da je cilj pre svega bio konkretizovati borbu između racionalizma i iracionalizma, fokusirajući borbu na pitanja praktičke filozofije. Ko je odneo pobedu u ovoj borbi ostaje pitanje interpretacije. Trifunovićeva inter-pretacija je da je pobedu odnela iracionalistička koncepcija Šopenhauerove i Ničeove filozofije.

Sledeće izlaganje održao je Nenad Ranković (Novi Sad) sa temom „Pesimizam vodi slabosti, optimizam nam daje moć”. Po Rankovićevim rečima, Vilijam Džejms, čiji je citat i sam naslov izlaganja, verovao je da je potreba za srećom ta koja čoveka tera da preuzme kontrolu nad svojim životom. Optimizam daje moć zato što nam ne dozvoljava da se predamo. Naime, uvek je moguć dolazak boljeg sutra. Pesimizam vodi slabosti zbog negativnosti i uverenja da bolje sutra nikada neće doći. Ranković želi da stavove o optimizmu i pesimizmu zadrži u granicama etike tvrdeći da je optimistički pogled na stvarnost jedini mogući uslov za srećan život $u$ inače okrutom svetu.

Iduće izlaganje održao je Panajotis Hrisopulos, (Nacionalni i kapodistrijski univerzitet; Atina) na temu „Emoticons and authenticity”. Izlagač tvrdi da je upotreba emotikona prerasla u etički problem. Tezu svog izlaganja autor brani stavom da izražavanje emocija preko interneta može biti ne-autentično. Naime, emotikoni su emocije prikazane preko ekrana. Zbog udaljenosti nemoguće je utvrđivanje pravih emocija osobe sa kojom se dopisujete i otvorena je mogućnost prevare. Druga perspektiva mogu-će opasnosti upotrebe emotikona predstavlja strah od rešavanja Turingovog testa. Naime, ako se veštačka inteligencija nauči da prikazuje 
emocije na valjan način, drugog postavlja kao nemoguć nemogućim bi se pokazalo utvrđi- zadatak, a samim tim mogućnost vanje razlike između čoveka i mašine tokom razgovora preko ekrana.

Poslednje izlaganje prvog dana konferencije održao je Igor Janković (Novi Sad) na temu „Strasti i fikcija u Hjumovoj filozofiji”". Izlagač je težio da prikaže (ne)mogućnost fenomena empatije u Hjumovoj filozofiji. Budući da Hjum ni u jednom svom delu ne govori o empatiji, Janković fenomen empatije postavlja u relaciji sa fenomenom simpatije. Autor tvrdi da se odnos simpatije i empatije pokazuje specifičnim u okvirima Hjumove senzualističke epistemologije. Referišući na Raspravu o ljudskoj prirodi i Istraživanje o ljudskom razumu, Janković tvrdi da je kod Hjuma jasno da se simpatija ograničava na sadržaje ličnog iskustva, ostajući u domenu intrasubjektivnosti. Ono što empatiju čini različitom jesu nedostatak sopstvenog iskustva i izgradnja emotivne veze $u$ intersubjektivnoj sferi. Izlagač završava tvrdnjom da se empatija kod Hjuma može razumeti jedino kao fikcija. Naime, u Hjumovoj epistemologiji se napuštanje lične tačke gledišta i uživljavanje u tačku gledišta nekog empatije ostaje u domenu onoga zamišljivog, ali ne i ostvarljivog, odnosno fikcije

Drugi dan konferencije otvorila je Anja Cmiljanović (student-kinja doktorskih studija filozofije; Filozofski fakultet u Novom Sadu) plenarnim izlaganjem na temu „Filozofski aspekti naučnog razumevanja emocija". Pol Tagard u knjizi „Mozak i smisao života” psihologiju i neuronauku postavlja kao ključne nauke zadužene za odgovor na pitanja emocija, sreće i - kako je naglašeno u samom naslovu knjige - smisla života uopšte. Cmiljanovićeva je stava da Tagardovo stanovište neuralnog naturalizma zapostavlja bitne filozofske aspekte razumevanja emocija. Autorka za primer uzima egzistencijalizam koji prikazuje suočavanja i reakcije na određene životne situacije. Izlagačica zaključuje da Tagard propušta da svoje stanovište ojača previđajući činjenicu da egzistencijalizam i fenomenologija mogu doprineti naučnom razumevanju emocija.

Sesiju je otvorio Aleksandar Prica (Beograd) sa temom „Volja za istinom i kult laži: Uloga intuicije, emocije i nagona u Ničeovoj 
epistemologiji i estetici”. Osnovna teza bila je opravdanje Ničeove ideje da filozofija treba da se koristi metaforičkim jezikom umetnosti, jer uz pomoć nauke, prema Ničeu, dolazimo do zabluda, a uz pomoć umetnosti dolazimo bliže istini.

Iduće izlaganje održala je Ana Lorger (komparativna književnost, Ljubljana) na temu „Love as code in Lessing's Emilia Galotti'. Autorka osećaj ljubavi razumeva kao glavni motiv drame Emilia Galotti. Zatim Lorger prikaz ljubavi povezuje sa socijalnom pozadinom likova iz drame. Referišući na delo Niklasa Lumana „Love as Passion”, autorka prikaz ljubavi iz Lesingove drame interpretira kao socijalni kod koji pruža pravila kroz koje se emocije iskazuju. Lorgerova zaključuje izlaganje ističući povezanost filozofskog razumevanja emocija i prikazivanja emocija u književnim delima.

Sledeća za govornicu izašla je Matija Vigato (Zagreb) sa temom „Empatija i videoigre”. Vigato je izlaganje započela naglašavajući da videoigre poseduju dvostruku prirodu, jer ih možemo posmatrati kao igre i kao umetnost. Izuzetan prikaz teze da su videoigre umetnost Vigato je načinila u svom master radu „Jesu li videoigre umjetnost" za koji je dobila prestižnu „Rektorovu nagradu Univerziteta u Zagrebu”. Ovoga puta, dosledno temi, Vigato se fokusirala na mogućnost manipulacije emocijama kroz medijum videoigara. Iako videoigre mogu posedovati negativan uticaj na emocije igrača dovodeći do desenzibilitacije, Vigato u izlaganju teži prikazati mogućnost pozitivnog uticaja videoigara na emocije, pre svega fokusirajući se na fenomen igara koje potiču empatiju.

Poslednje izlaganje $u$ sesiji održao je Nenad Lančuški (Novi Sad) sa temom „Pojam filozofske drame". Uzimajući za primer Sartrovu dramu „Prljave ruke”, autor je prikazao mogućnost povezivanja filozofije i teatra. U filozofskoj drami poznatoj i kao teatar situacije, nije važno zašto je dramski lik nešto uradio nego šta je uradio. Fokusirajući se na „šta” delanja drama ima potencijal prikaza filozofskih stanovišta kao objekata dramske radnje. Lančuški tvrdi da se najveća prednost transformacije filozofskih koncepata u akcije dramskog lika nalazi u pojačanoj emocionalnoj reakciji od strane publike. Lančuški zaključuje stavom da se filozofska drama pojavljuje kao način primenjene 
filozofije, kao filozofija koja u žanru drame provocira gledaoce na mišljenje filozofskih ideja.

Naredno izlaganje održala je Zorica Matoš, (Novi Sad) na temu „Aristotelovo zasnivanje etike". Cilj izlaganja bio je prikaz Aristotelovog zasnivanja etike i praktičke filozofije in generis. Matoš u izlaganju tvrdi da je Aristotel prvi filozof koji je shvatio da znanje bez htenja ne može da bude pokretačka osnova za delanje. Pokretačka osnova za Aristotela je umska želja koja predstavlja sintezu razumskog i nerazumskog dela duše. Autorka zaključuje da Aristotel prvi shvata prirodu ljudskog delanja na predočen način te da prikazuje posredovanje želja i nagona zarad ostvarivanja procesa navikavanja na fronetičko delanje.

Poslednje izlaganje u sesiji održao je David Menčik (Novi Sad) na temu „Uticaj različitih društvenih okolnosti na antičke filozofske stavove o nadvladavanju emocija". Menčik tvrdi da su društvene okolnosti u kojima su živeli Platon, rimski Stoici i Boetije potpuno različite i da su motivi za nadvladavanje emocija kod pomenutih filozofa plod različitih društvenih okolnosti. Platonovi motivi su političke i psihološke prirode. Politički motiv se pronalazi u Platonovom uviđanju da naglašenost emotivnih reakcija epskih junaka može imati negativne posledice za polis. Psihološki motiv prisutan je u dijalogu Fedon u kojem Sokrat tvrdi da je jedino onima koji teže nadvladavanju telesnog omogućen boravak u svetu ideja. Zatim, u filozofiji Seneke i Epikteta jasno je prikazan etički motiv suzdržavanja od emotivnih odgovora na bilo kakvu društvenu situaciju koja nas može zadesiti. Konačno, Boetijev motiv za nadvladavanje emocija je egzistencijalne prirode. Boetija kao osuđenika na smrt ne zanima boljitak u zajednici, a nadvladavanje straha i besa prema sudbini rezultira u ozdravljenju duše.

Poslednju sesiju otvorili su Ana Daria Bokan i Josip Periša (Zagreb) sa temom „Ljudska destruktivnost i emocionalnost umjetne inteligencije". Temi je prvi pristupio Periša koji je u postavio pitanje da li su destruktivnost i agresija emocije urođene ljudima. Periša tvrdi da je izvor agresije frustracija. Pošto se deca ne rađaju frustrirana, autor tvrdi da je agresija stečena emocija. Upravo stečenost agresije dovodi do različitog stepena agresivnog ponašanja od 
pojedinca do pojedinca. Periša brani svoje stanovište na primerima odrastanja nekih od agresivnijih ljudi $\mathrm{u}$ istoriji. $\mathrm{U}$ drugom delu izlaganja Bokan, slikovitim prikazom iz prakse, pokazuje primere u kojima je veštačka inteligencija stvorena tako da bude destruktivna i primere u kojima nedestruktivna veštačka inteligencija vremenom stiče destruktivno ponašanje.

Iduće izlaganje održala je Sara Svati Sharan (Ljubljana), na temu „Stražnja strana govora: šutnja”. Izlaganje je započeto razlikom tišine i ćutanja. Autorka tvrdi da je ćutanje za razliku od tišine intersubjektivno oruđe. Ćutanje poseduje stav, koji se izražava u formi ne-govorenja. Izlagačica tvrdi da ćutanje može da poseduje retoričku vrednosti, u smislu govora telesnim gestovima. Zatim ćutanje može biti izraz mudrosti, motiv koji je najbolje prikazan u pitagorejskoj filozofiji. Treći način delovanja ćutanjem je prisilno ćutanje koje se javlja kada emocionalno stanje ne može biti iskazano rečima. Za kraj neophodno je pohvaliti hrabrost koju je Sara pokazala kako bi se prevazišla jezička barijera.

Poslednje izlaganje na konferenciji održao je Luka Rudić (Novi
Sad) izlažući na temu „Lakan o ljubavi". Referišući na Lakanov članak „Četiri temeljna pojma psihoanalize", Rudić za cilj izlaganja postavlja poduhvat konstrukcije sistematskog razumevanja ljubavi kod Lakana. Povezujući Lakanov pojam transfera sa Platonovim mitskim prikazom rođenja Erosa iz dijaloga Gozba, Rudić tvrdi da je Eros, a stoga i ljubav, spoj imanja i ne-imanja. Budući da se ljubav razumeva preko pojma transfera, Rudić zaključuje da bi ljubav bila davanje nečega što nemamo - samim tim ništa.

Zaključnu reč na konferenciji imao je Lazar Atanasković, asistent na Odseku za filozofiju u Novom Sadu. Atanasković je pohvalio raznolikost tema prikazanih na konferenciji i pozvao izlagače da svoje izlaganje pretoče $\mathrm{u}$ formu naučnog rada koji će nakon postupka recenzije biti objavljen $\mathrm{u}$ posebnom zborniku izlaganja sa konferencije Summa Studiorum Philosophiae. 